\title{
CONVIVENCIA CIUDADANA VERSUS NARCISO: LA BATALLA POR UN ORDEN CIVIL PACÍFICO E IGUALITARIO
}

DEIVIS BOLIVAR RANGEL ${ }^{1}$

\section{RESUMEN}

Se presenta la perspectiva que sobre el mal, como tendencia vanidosa en el fuero íntimo de la psiquis humana, ofrece la filósofa Martha Nussbaum. En torno de dicho referente conceptual, se muestra cómo el ideal de convivencia ciudadana se ha visto trastocado por quienes dividen el mundo, en un arrebato narcisista de asco proyectado, entre lo puro y lo impuro; y por quienes jerarquizan la dignidad en función de supuestos niveles de contaminación percibidos en un otro amenazante. Se ilustra cómo esa misma reacción narcisista se camufla en aquel proceder legalista que asegura estar consagrado al respeto por la diferencia; y se señalan aspectos negativos dentro de la educación en valores que precisan un re direccionamiento a fin de dotar a la ciudadanía de herramientas eficaces para vencer su propensión al egoísmo vanidoso.

Palabras clave: Vanidad, Desarrollo humano, Pacifismo civil, Diferencias.

\footnotetext{
${ }^{1}$ Filósofo, Universidad del Atlántico (Colombia). Candidato a magíster en Literatura y cultura, Instituto Caro y Cuervo (Colombia). Asociado a la Escuela Galán para el Desarrollo de la Democracia. Consorcio para la paz, calle 48 \# 16-24. Código Postal: 111711, Bogotá, Colombia. Correo electrónico: deivis.philosopher@gmail.com
} 


\section{NARCISO VERSUS COEXISTENCE: THE BATTLE FOR A PEACEFUL CIVIL ORDER AND EQUAL}

\section{ABSTRACT}

The perspective on evil as conceited trend in the heart of hearts of the human psyche philosopher Martha Nussbaum offers is presented. Around this conceptual reference, it shows how the ideal of peaceful coexistence has been subverted by those who divide the world into a narcissistic outburst of disgust projected, between pure and impure; and those who nest dignity assumptions based on perceived levels of pollution threatening another. It illustrates how the same narcissistic reaction camouflages in that proceeding that ensures legalistic be devoted to respect for difference; and negative aspects are highlighted in values education who require re routing to provide effective citizenship to overcome his propensity tools conceited egotism.

Keywords: Vanity, human development, civil Pacifism, Differences.

\section{Reflexiones introductorias}

Motivos de sobra parecía tener el poeta rumano Emile Ciorán para abortar sin contemplaciones, en uno de sus aforismos, cualquier posibilidad de ponerse en los zapatos del otro, de padecer con el otro; que es a lo que etimológicamente nos remite el término “compasión”. El ser capaz de "padecer con el otro" es una de las demandas más acuciantes de las sociedades contemporáneas: justamente la experiencia de tantas e insolubles refriegas étnicas, religiosas e incluso estéticas que son tema noticioso a lo largo y ancho del globo, nos revelan que las fórmulas políticas actuales están muy lejos de ser esos cimientos sólidos que, más allá de su formulación teórica, verdaderamente sustenten a las democracias liberales y las mantengan rozagantes en términos de orden público y libertad expresiva. El fragmento dice así: "No juzgues a nadie sin antes haberte puesto en su lugar. Este viejo proverbio invalida cualquier juicio, pues sólo juzgamos a alguien porque, justamente, no podemos ponernos en su lugar" (Cioran, 1998, p. 85). 
Se puede sostener que los motivos de Ciorán, suministrados por su propia experiencia de vida y el sentido común, son los mismos que ha encontrado la ciencia biológica del comportamiento homínido en sus más recientes investigaciones sobre desarrollo humano, pues ha concluido que a los hombres nos queda difícil desplegar cualquier sentimiento de compasión por alguien que no se encuentre ubicado dentro de nuestro reducido radio afectivo. $Y$ en eso somos semejantes a aquel ratoncito que fue usado en el marco de los experimentos mencionados ${ }^{2}$, y que se mostró cero condescendiente con un ejemplar en peligro de su misma especie, mas no perteneciente a su misma madriguera, luego de haberse mostrado solidario, en un primer episodio, con un ejemplar (también en peligro) con el que sí compartía espacio.

Eso mismo se advierte en el despliegue limitado de compasión y empatía por parte de algunos grupos sociales: "algunas personas de raza blanca, por ejemplo, son capaces de sentir gran comprensión por otras personas de su raza, y, al mismo tiempo, de tratar a las personas que no son de su raza como si fuesen animales u objetos, negándose a ver el mundo desde su perspectiva" (Nussbaum, 2014, p. 65).

En consecuencia, entre los diversos rasgos compartidos con otras especies se encuentra la falta de compasión respecto del extraño y diferente. Este rasgo permea, en todo momento, nuestro comportamiento social, nuestras relaciones interpersonales y nuestras competencias interculturales. Este patrón conductual se replica en casi todas las especies que habitan la tierra, y, según Nussbaum (2014), parece residir en lo más profundo de nuestra herencia evolutiva.

Si bien ese rasgo conductual es común a casi todas las especies, según lo considera Nussbaum, sorprende que, para el caso de los hombres, dicha respuesta (que puede calificarse de "vanidosa"), haya sido legitimada por marcos teóricos que a la hora de explicar la génesis de la vida en sociedad

\footnotetext{
${ }^{2}$ Nussbaum cita el experimento llevado a cabo por un grupo de etólogos como un argumento de corte experimental que refrenda su tesis. El proyecto se llamó Social modulation of pain as evidence for empathy in mice, y los resultados de dicho experimento fueron publicados en el año 2006 en el volumen 312 de Science, entre las páginas 1967 y 1970.
} 
(como es el caso del contractualismo clásico) adujeron el miedo (Hobbes), el interés, la seguridad, la propiedad (Locke), o en últimas el beneficio como sus razones fundacionales. Pues tales planteamientos dan cuenta de un ser que despliega al máximo sus cualidades empáticas dentro de los márgenes de su vida privada, pero que restringe estas mismas cualidades en calidad de negociante dentro de sus relaciones públicas con sus conciudadanos. Ello deviene una versión de humanidad bastante sesgada, dirá Martha Nussbaum en su obra Las fronteras de la justicia (2012), refiriéndose a la noción de Estado propuesta por la nómina iusnaturalista de los siglos XVII y XVIII, cuyos sesgos redujeron las posibilidades semánticas de la justicia hasta nuestros días, al no incluir dentro de su geografía conceptual un lugar para los discapacitados, los animales no humanos, entre otros aspectos que escapan al club del mundo racional, pero a cuyos dominios cabe extender nuestra humanidad.

Contrario a ese sesgo, Nussbaum destaca enfáticamente que nuestros dotes humanos no terminan donde acaban los impulsos más primitivos de nuestra estructura biológica o de nuestra psicología evolutiva, aquellos esquemas que trazan intereses defensivos inmanentes al deseo de supervivencia. La autora menciona que nos redime de tales procederes, y nos dota de visión moral, la razón, la capacidad de autoidentificarnos, la autoconciencia que sobreviene o que anticipa nuestras elecciones más elementales.

De acuerdo con Nussbaum (2015:

Aunque no puede negarse que en gran parte somos seres necesitados, confusos, incontrolados, enraizados en la tierra e indefensos bajo la lluvia, hay en nosotros algo puro y puramente activo, que podemos llamar 'divino, inmortal, inteligible, unitario, indisoluble e invariable. Parece que ese elemento racional podría gobernar y guiar el resto de nuestra persona, salvándonos así de vivir a merced de la fortuna. (p. 30)

De ahí que no resulte del todo romántico hablar de estas cosas como deseables y posibles, ni que depositar una mínima cuota de confianza en el género humano merezca un retorcijón censurante de labios, como suele ocurrir en los momentos y los espacios en los que se ponen sobre la mesa estas 
mismas cuestiones. Está claro que la confianza en el hombre no debe generarse desde una óptica nutrida del lugar común desde donde proliferan toda clase de discursos entusiastas sobre tolerancia y respeto, discursos que no se molestan siquiera en hacer un sondeo serio de todo cuanto involucra ser humanos y ser instruidos para vivir en sociedad. Una indagación más profunda es lo que precisamente sí hace Martha Nussbaum en el marco de su filosofía educativa: ésta toca las puertas de saberes contiguos a su disciplina, con el ánimo de cubrir la solución al problema de que se ocupa en todas sus dimensiones posibles.

\section{Los aspectos psico-biológicos del mal según Nussbaum}

Martha Nussbaum se detiene a analizar una particularidad dialéctica de nuestra especie: por un lado, las habilidades cognitivas que compensan nuestra fragilidad anatómica, y que hemos sabido poner al servicio, por milenios, de nuestra seguridad y bienestar; por el otro, la sensación de sabernos cuerpos precarios. Precisamente son estos aspectos los que le suman complejidad al hombre, y vuelvan estrecha la simple equiparación de un ser humano con el resto de las especies, en lo que a materia comportamental concierne.

Como se ve, en el hombre confluyen dos aspectos que determinan la manera como este se relaciona con el mundo y que despiertan la necesidad de trazar, además, un plan defensivo respecto del mundo que lo rodea: por un lado, el sentimiento de indefensión que sobreviene en el niño al saberse incapaz de caminar, de andar, de apropiarse autónomamente de los objetos de su entorno; y por el otro, el sentimiento de superioridad intelectual que lo asalta al saberse dueño de un lenguaje que nombra cosas y percepciones como también de pensamientos recursivos.

Es esta una conjunción problemática que va estructurando en la mente del niño una propensión defensiva (casi automática) a decantarse únicamente en favor de aquellos aspectos que lo engrandecen como especie, y a negar aquellos que le recuerdan su mortalidad y su vulnerabilidad fisiológica en tanto que cuerpo degradable y portador de desechos, o, más exactamente, a proyectar estos últimos aspectos sobre los 
demás ejemplares de su especie, respecto de los cuales él mismo quiere calificarse como excepción al pretender liberarse del contenido "indecente" para impugnárselo a otros.

Ahora bien, esa esquematización que hace Nussbaum de la interacción (en esencia conflictiva) hombre-sociedad hunde sus raíces en la premisa fundamental del psicoanálisis, según la cual, la pregunta por el origen de la civilización nos remite a un conflicto existencial librado hacia las primeras etapas de la infancia. Luego de esa disputa temprana, salen finalmente gananciosas la repugnancia y la vergüenza hacia todo lo que nos recuerde ser humanos en el sentido cabal y primitivo del término: comenzamos a editar con el recurso de la perfumería nuestros hedores corporales legítimos para seducir olfatos vecinos, acudimos al artilugio de los cubiertos para evitar ensuciarnos las manos mientras comemos, a mantener nuestras heces y secreciones en celoso secreto, a alivianar los instintos sexuales más primitivos, a cubrirnos la cara cuando brotan las lágrimas, a no exponer públicamente nuestros genitales (el resto de las especies los llevan descubiertos con la frente en alto), y a disimular en lo posible las asociaciones libres que opera la mente respetando el principio de coherencia y temiendo ser tildados de anormales.

En fin, ponemos en marcha un sinnúmero de mecanismos fundacionales de lo que tenemos a bien llamar "civilización" o "comportamiento civil", el cual refina cada vez más, con el paso de las generaciones, sus implicancias. Según la apreciación de largo aliento histórico que ofrece el sociólogo Norbert Elías -en su obra El proceso de la civilización (2001), y que Nussbaum cita con ocasión de sus propios argumentos en El ocultamiento de lo humano (2006) - puede considerarse como desatino erigir dicho asco como criterio para despachar condenas dentro del derecho penal.

Es en ese meollo conceptual —respaldado por investigaciones recientes en el ámbito de la psicología experimental, como la mencionada más arribaen el que Martha Nussbaum encuentra la piedra angular para dar cuenta de las causas de la tendencia a la maldad, a la injusticia, a la tiranía, y a la corrupción política que aqueja a muchos estados mundiales y hasta a los 
mismos sistemas educativos. Sobre todo, estos últimos, advierte la filósofa, están sujetos cada vez más a directrices curriculares que terminan afianzando excesivamente la disposición problemática a dividir el mundo entre lo puro y lo impuro, lo limpio y lo sucio ${ }^{3}$; y a atacar a otros grupos humanos en nombre de tales distinciones narcisistas porque los suponemos, en consecuencia, agentes contaminadores que amenazan con percudir nuestra supuesta pureza. Sin embargo, de lo que verdaderamente hay que defenderse, apunta Nussbaum, es de esa respuesta vanidosa que hace estragos en la psiquis de los individuos y que se replica a gran escala social de no ser moderada a tiempo mediante una educación sólida en valores como la empatía, el perdón y la compasión.

\section{Las disposiciones conductuales entre lo psicológico y lo político}

De lo dicho anteriormente, se sigue que la batalla que debe ganar la apuesta por una convivencia ciudadana que avizore el respeto mutuo y el pacifismo civil como banderas de la democracia, se libra, antes que en predios externos a la propia mente, en el fuero íntimo de cada individuo. Es decir, comienza con la invitación socrática que reza Conócete a ti mismo, para que no seamos ese sujeto que descaradamente admite: "Tengo todos los defectos de los demás, y, sin embargo, todo lo que hacen [ellos] me parece inconcebible" (Cioran, 1998, p. 36).

\footnotetext{
${ }^{3}$ En Colombia, por ejemplo, no es un secreto que los centros de formación primaria y secundaria, tanto a nivel público como privado, se mantienen anclados a una enseñanza de la religión vista exclusivamente desde la perspectiva del cristianismo y del catolicismo como verdades últimas del hombre, lo cual deviene una incompetencia intercultural en los estudiantes a la hora de tener que valorar o pronunciarse sobre otras cosmogonías que igualmente tienen todo el derecho de existir y de vincular moralmente a comunidades humanas que se encuentran por fuera de su radio geográfico, o incluso dentro, como lo es el caso de las etnias con las que compartimos territorio nacional, mas no principios ontológicos que den cuenta de un mismo marco explicativo de la naturaleza. Sucede de la misma forma en los programas académicos ofertados por claustros universitarios. Estos están volcados casi en un ciento por ciento a los contenidos específicos de la disciplina ofertada, y no contemplan saberes que puedan convertir a sus futuros egresados en sujetos críticos de su propia situación histórico-cultural con respecto a las de otros hombres con los que comparten el planeta, y a los que interpelan indirectamente con sus decisiones económicas y convicciones políticas. No existen referencias, siquiera básicas, de otras filosofías aparte de la occidental, de otras culturas aparte de la latinoamericana y la europea; con lo que se promueve, por omisión, toda suerte de nacionalismos chauvinistas y prejuiciosos que jerarquizan entre modos de vida menos y más dignos, y que se alimentan precisamente de ese mismo relato narcisista del que venimos hablando, de cuyos peligros morales nos alerta Nussbaum.
} 
Nussbaum (2014) da un ejemplo que va en la línea contraria de ese sujeto:

Mahatma Gandhi, uno de los dirigentes democráticos más creativos del mundo, que se encontraba entre los principales arquitectos de la independencia y la democracia en la India, sabía muy bien que la lucha por la libertad y la igualdad debía configurarse primero como una lucha interna en el fuero íntimo de cada persona, donde se enfrentaban la comprensión y el respeto con el miedo, la codicia y la agresividad narcisista. En numerosas ocasiones, Gandhi señaló la relación existente entre el equilibrio psicológico y el equilibrio político. (p. 54)

La autora quiere decir con lo anterior que hay que sintonizar la psicología de las personas reales, con la psicología política (o conciencia colectivizada) que institucionalizan los diferentes organismos del Estado, pues de la buena voluntad de los ciudadanos depende en gran medida qué tipo de normas, relativas a lo que es ser un ciudadano bueno y razonable, son las que llegan a incorporarse y a regir las conductas en dichas instituciones. $Y$ al revés: de cuáles sean específicamente tales concepciones del hombre fijadas como pautas ciudadanas en la sociedad por parte de los organismos mencionados depende en gran medida qué tan dispuesta llegue a estar la voluntad de los ciudadanos hacia un respeto liberal por la igualdad humana. $O$ en otros términos, significa que las dos instancias se complementan en lógica de afectación bilateral o circular. En cierto modo, se asemeja a la idea de la microestructura y superestructura de que hablara Marx, que van de la mano como sustratos materiales del desarrollo histórico de cualquier nación.

Tipifico lo anterior con un caso que cita Nussbaum en El ocultamiento de lo humano (cfr. 2006, p. 63): el sistema penal acusatorio de Texas, hasta el año 1973, excarcelaba a aquellos hombres que en un rapto de celos asesinaran al amante de su cónyuge por haberla sorprendido en flagrancia cometiendo adulterio. Ese código favoritista, o bien trasunta una idea de la mujer texana como objeto, extensión y posesión del género masculino que circulaba de antemano en las fibras sociales más finas de esa comunidad, o bien llegó a promocionar una forma de violencia contra la mujer texana dentro del sistema penal como práctica que no implicaba judicialización alguna, y 
justificándose en los supuestos de una ira racional que deja entrever, además, una versión acomodaticia de razón en el contexto texano para aquel entonces.

En cualquiera de los casos, no es detectable en términos estrictos qué estuvo primero encima de qué direccionando las decisiones de una comunidad hacia la violencia de género (causas y efectos mutan y se sedimentan siempre bajo una perspectiva histórica), pero sí se advierte a todas luces un desequilibrio político en el mismo momento en que el aparato jurídico del Estado en cuestión osó licenciar una práctica que elevaba exponencialmente las tasas de homicidio (la jurisprudencia estaba a cargo de hombres texanos con las mismos imaginarios de superioridad masculina insertos desde la infancia), a sabiendas de que ello traducía una tragedia pública, que a su vez acarreaba otras consecuencias sociales seguramente difíciles de aplacar.

$Y$ es por falta de ese equilibrio que cargamos sobre nuestras espaldas un pasado belicoso (dos guerras mundiales solo en el siglo XX), cuyas lógicas se siguen replicando en nuestro presente bajo la forma de crisis humanitarias y económicas, en las que se deja entrever Narciso o el espíritu de la vanidad licenciando al sentimiento de la vergüenza para cometer los hechos más atroces hacia nuestros semejantes.

\section{Experiencias narcisistas del pasado y del presente}

Investigaciones recientes sobre los patrones conductuales del nazismo, y el modo como éstos germinaban en los jóvenes militares alemanes convocados a las brigadas genocidas, aseguran que "en el caso de esos jóvenes, la influencia de la autoridad y la presión de sus pares eran tan enormes que quienes no lograban dispararles a los judíos se sentían avergonzados de su propia debilidad" (Nussbaum, 2014, p. 69).

En cuanto a episodios del mismo tipo, América latina durante el periodo colonial (y todavía poscolonial) es un manantial de ejemplos. La literatura de viajes durante el boom de las expediciones botánicas y geográficas en "el nuevo mundo", a cargo de ilustres científicos y letrados como Humboldt, Francisco José de Caldas y Gonzalo Jiménez de Quesada (por nombrar solo algunos), constituye todo un corpus testimonial de la presencia de Narciso. 
Ojos imperiales, los llama Mary Louis Pratt (2010), al destacar que la escritura de muchos de estos expedicionarios, por lo general, fundaban un principio al mejor estilo de Dios en la descripción del libro Génesis. Sus discursos trazaban un imaginario que barría con todo presupuesto o precedente nativo; es decir, que su llegada le daba el derecho a esta parte del mundo de inscribirse en el tiempo. Antes, no tenía forma de probar que existía, pues no había patente escritural que así lo patentara. Así las cosas, se tropezaban con el nativo como un accidente, como un objeto sin voz que hacía parte del decorado de la naturaleza "descubierta" y que (debido a que no tenía alma) quedaba a la disposición instrumental de ellos.

Por ejemplo, "en la narración de la crónica de Indias que cuenta cómo la mente conquistadora europea penetra la espesura adversa del Nuevo Mundo, el Yo de la conciencia escrituraria nunca deja de ser el centro generador de sentido" (Moreno, 2015, p. 30).

Aquella superioridad fundacional del ánimo colonialista, se comprueba en un hecho que destaca Ángel Rama (1998). En el territorio americano:

no se reconstruía el proceso fundacional de las ciudades que había sido la norma europea, sino que exactamente lo invertía; en vez de partir del desarrollo agrícola que gradualmente constituía su polo urbano donde se organizaba el mercado y las comunicaciones al exterior, se iniciaba con esta urbe. Por eso, serán todos desde el principio hidalgos, se atribuirán el don nobiliario, desdeñarán trabajar por sus manos y simplemente dominarán a los indios que les son encomendados o a los esclavos que compren. (pp. 25-26)

Este posicionamiento urbanista abrupto como garante del ocio imperial, promueve la división entre lo rural o agreste, como sede de lo impuro o bárbaro; y lo urbano, como sede de la más pura espiritualidad progresista y alejada de la animalidad instintiva de los nativos, con quienes se debe mantener una distancia equivalente a la que se aprende a tener respecto de los desechos que el propio cuerpo esputa. Bernardo de Balbuena, citado por Rama, escribe en 1604 estos versos: "Si desea vivir y no ser mudo/ Tratad con sabios que es tratar con gentes/ Fuera del campo torpe y pueblo rudo" (Ángel 
Rama 1998, p. 32).La misma reflexión hace el crítico literario Juan Moreno Blanco (2015), pero ya más hacia el periodo poscolonial:

Se acaba la colonia, el imperio se retira. Pero la derrota militar y política de España no significa que el mundo americano que pensó el español haya desaparecido. Muchas cosas quedan: la lengua, la religión católica, la infravaloración del Otro lejano racialmente al "blanco" y, entre tantas otras cosas más (p. 29).

Todos esos elementos suprimen, desde el dispositivo de la escritura, y con la misma lógica de antaño, cualquier posibilidad de que los nativos, los africanos y los grupos resultantes de las muchas mezclas genéticas tengan participación y garantías efectivas en la construcción de una sociedad libre en los años posteriores a los movimientos independentistas. Todos esos elementos difunden, desde el complejo criollo, la idea de una "superioridad blanca".

De igual manera, Rama (1998) plantea que:

Trescientos años después (del comienzo de la colonia), y ya en la época de los nuevos estados independientes, Domingo Faustino Sarmiento seguirá hablando en su Facundo de las ciudades como focos civilizadores, oponiéndolas a los campos donde veía engendrada la barbarie (p. 26).

Pero, no hay necesidad de ir muy lejos en el tiempo: hoy el ideal criollo poscolonial, montado sobre la vanidad narcisista de las divisiones jerárquicas entre razas más o menos limpias, aun después de haber sido arrasado en teoría por la arremetida constitucional de 1991, continúa cobrando víctimas en algunos pedazos de geografía nacional sumidos actualmente en el olvido y la miseria: El Pacífico, el Norte de Antioquia, Buenaventura, El Amazonas, La Guajira... periferias todas por excelencia. Es más, hoy sobreviven vestigios de ese ideal vanidoso en el trato que les damos a los grupos asentados en sectores rurales: la imagen de la campesina con trenzas y mejillas asoleadas que carga cántaros de leche y maltrata el castellano es motivo de burla entre los civilizados, es una caricatura de lo tosco, lo primitivo, lo poco inteligente; lo que se designa peyorativamente con el adjetivo montañero cuando queremos tratar a alguien de inculto. 
Ahora bien, si analizamos el contexto internacional, tenemos que las crudas políticas migratorias no dejan de invocar el mismo espíritu narcisista patente en el ejemplo anterior. Éstas desencadenan grandes tragedias y dramas humanos en muchas fronteras del mundo, pero sobre todo forjan en el imaginario colectivo de las naciones buscadas como refugios promisorios una percepción del extranjero autoexiliado como intruso que intenta desestabilizar el orden prístino que han sabido construir aquellos con más tesón e inteligencia que los países de donde provienen los migrantes (a los que hay que mantener al margen de las oportunidades económicas decentes en caso de que logren cruzar la frontera, pues nunca se sabe, y siempre se temen, cuáles puedan serlas consecuencias de su influjo simbólico sobre el 'intachable' imaginario nacional).

Dicha percepción se afianza en los ciudadanos privilegiados. En principio porque estos últimos ignoran por completo las grandes injusticias internacionales que arremeten a diario contra los países menos desarrollados en nombre de la competitividad y del libre intercambio, de los malentendidos diplomáticos y de otras etiquetas propias del lenguaje de la globalización, como bien lo resume en una frase sabia Rabindranath Tagore: "Todas las grandes naciones de Europa tienen sus víctimas en otras partes del mundo". Los primeros no comprenden que "en muchos casos las oportunidades de los habitantes de distintas geografías están determinadas por condiciones que éstos no eligieron, y obedecen más bien al papel histórico del colonialismo, al rol actual de las inversiones extranjeras y de las empresas multinacionales" (Nussbaum, 2014, p. 117).

Siguiendo la línea de los ejemplos, no hace falta ser psicólogo social para advertir que ese mismo imaginario narcisista es el que ha cartografiado la dignidad humana en consonancia con el juego de la economía. Y lo menciono a propósito de la discusión reciente sobre la nivelación de los salarios entre técnicos, tecnólogos y profesionales que suscitó la propuesta del Sistema Nacional de Educación Terciaria (SNET), presentada por los Ministerios de Educación Nacional, Trabajo y TIC (Sección Educación, 2016). En ese momento, el país abogó enérgicamente (sobre todo a través de 
redes sociales) por la perpetuación de los hondos contrastes que siempre han existido en materia salarial dentro del territorio nacional ${ }^{4}$. Esto es una muestra de que, en efecto, Colombia necesita tales contrastes; que los aclama como un recurso que le asegura cada tanto fuertes dosis de superioridad frente a sus semejantes, como bien lo ilustra Carolina Sanín (2008) a través de la figura de 'la muchacha del servicio' y la violencia simbólica a la que ésta es sometida por parte de sus 'caritativos patrones', los que de paso se regodean de la bondad inmerecida que profesan hacia ella: '¿qué más quiere esa aparecida?' - se preguntan indignados-. 'Si ya bastante tiene con que le hagamos el favor de sentirse como en familia', aunque no lo sea: es el mensaje narcisista que se esconde tras ese tipo de relaciones verticales.

Esta patología que se alimenta de los fuertes contrastes, como ocurre con Colombia respecto de la conciencia axiológica jerarquizante que subyace a la división del trabajo, asoma también en la forma misma como circula socialmente el ideal de ciudadano exitoso (en la forma como se verbaliza o grafican las aspiraciones), en contraste con el que a duras penas merece tres pesos y encima el adjetivo de "fracasado", "inculto", o de que no hace los méritos suficientes como para poder reclamar igualdad y una vida digna, satisfecha por lo menos en sus necesidades básicas.

Sorprende que sea en el mismo ámbito educativo donde Narciso encuentra vía libre para desarrollarse en ese sentido: por ejemplo, durante mi experiencia como asesor curricular dentro del proyecto 891, suscrito entre la Secretaría de Educación Distrital de Bogotá y diecisiete universidades de la capital, que tenía por objeto ajustar detalles para el cumplimiento cabal de la política pública del currículo para la excelencia 40 por 40 en instituciones oficiales, fui testigo del modus operandi de aquellos dispositivos que coadyuvan en el día a día a que los contrastes narcisistas de los que venimos hablando sigan afianzándose en el comportamiento ciudadano.

\footnotetext{
${ }^{4}$ Aun cuando la discusión nacida del Ministerio de Educación Nacional hablaba más bien de las condiciones laborales, la ciudadanía, en su gran mayoría, interpretó el tema como una equiparación igualitaria injusta en materia salarial, y reaccionó acaloradamente, aduciendo la dignidad, y reduciendo el sentido de una propuesta a la parte financiera, que no estaba siquiera explicitada en los términos en que fue interpretada.
} 
En la reunión que sostenía con una de las coordinadoras para comenzar a aplicar en su colegio el enfoque diferencialy de educación para la ciudadanía, contemplados como ejes transversales de todo el programa, irrumpieron dos estudiantes de décimo grado en la biblioteca. Cada una de ellas con una escoba en las manos. En el acto, la coordinadora les preguntó ofendida que quién las había mandado a barrer. Ellas respondieron que uno de los profesores les había ordenado la actividad como parte del servicio social. Ella les arrebató las escobas, les 'aclaró' que eso no hacía parte de ningún servicio social, y las devolvió a su salón de clases, prometiéndoles encima que hablaría con el respectivo docente que tuvo la osadía de rebajarlas a tanto.

En ese momento, yo me pregunté mentalmente si acaso barrer el piso de una biblioteca no era servirle a la sociedad de alguna manera. Incluso, lamenté la ofensa indirecta que pudo haber lanzado la coordinadora a una madre que probablemente estuviera educando a su hijo dentro de ese mismo plantel porque trabajaba como aseadora. ¿Merecía esa madre hipotética ese gesto de irrespeto, rechazo y vanidad por parte de la coordinadora?

Pues, resulta que esa actitud narcisista lleva decenios y decenios haciendo carrera en nuestra sociedad. Muy en el fondo sabemos que no debe existir una determinación azarosa vista como error a la hora de incorporarse a la vida laboral, como suele ocurrir con ocupaciones como el cuidado a la tercera edad, el servicio doméstico, la transportación terrenal de bienes, etc. Pues esas labores revisten hoy, y aun sabiendo que son imprescindibles para la sostenibilidad de cualquier economía, una etiqueta de desgracia, de fracaso y marginación tales que no merecen una remuneración digna por tratarse de opciones azarosas y 'fáciles', por tratarse supuestamente de la desembocadura natural de no haber hecho el mínimo esfuerzo por ingresar al juego de la economía mundial con la artillería legítima: cartones universitarios; que en nuestro caso colombiano son el pasaporte para acceder a la candidatura (apenas a la candidatura) de una posible vida digna y respetable, y al mismo 
tiempo un dispositivo de exclusión y marginación social que sacia las ansias imparables de jerarquías ya ejemplificadas en líneas anteriores.

En conclusión, hoy cualquier intento por echarle un vistazo crítico a la sociedad en sus dinámicas fundamentales de cooperación, se ven limitados por llevar puestas las gafas miopes que nos impuso la idea del "mérito", de la competencia y de la carrera individualista por el éxito económico, narcisistas todas en esencia. Sin embargo, alienta decir que al rescate de ideas como la cooperación y la reciprocidad, han consagrado recientemente su pluma valientes pensadores y líderes mundiales en materia de desarrollo, entre ellos la filósofa Martha Nussbaum y los economistas Amartya Sen y Manfred Max Neef. De modo que intervenir esos dominios políticos, sociales y económicos en los que ya ha hecho suficiente mella Narciso es el reto que enfrenta hoy la educación como bien público: "adentrarse en las profundidades de la psiquis individual para interrogarnos acerca de qué podemos hacer a fin de que la comprensión y la empatía le ganen la batalla al miedo y al odio" (Nussbaum, 2014, p. 71), y lograr, en lo posible, un orden civil pacífico.

\section{El reto de la educación}

En respuesta de todo lo expuesto anteriormente, es preciso dotar la sensibilidad de los ciudadanos de ese sentimiento trágico que implica vivir en los términos en los que le son dables vivir a cualquier ser humano: conviviendo sin remordimiento alguno con la conciencia de saberse y sentirse vulnerable, necesitado, complementado. A su vez, entendiendo lo humano como una condición de incompletitud compartida; aprendiendo a negociar genuinamente con ese tipo de sensaciones antes que esconderlas, proscribirlas o maquillarlas mediante la imposición de un poderío tiránico y absurdo sobre los demás, para entonces alejar de sí el sentimiento de debilidad que lo acosa a todo momento y consolarse con una idea ficticia de superioridad y autosuficiencia absolutas que, dicho sea de paso, no se corresponde en lo más mínimo con las dinámicas reales con que funciona la vida en sociedad, activadas siempre en lógica de reciprocidad; ni mucho menos "se condice con la vida humana tal y como la conocemos, con su inmanente proclividad a la precariedad física" (Nussbaum, 2006, p. 27). 
Respecto de esa última idea, cabe mencionar que Nussbaum exalta los efectos ejemplares de la tragedia griega como catalizadores de los buenos sentimientos ciudadanos: en la medida en que esta forma artística estaba contemplada dentro de la agenda pedagógica de los atenienses y no era un objeto de puro goce estético. Su principal función, reconoce incluso el propio Aristóteles dentro de su Poética, era inducir una purga emocional catártica en el espectador, una activación de su imaginación empática en relación con los hechos que ponían al límite la vida del héroe trágico en escena, y que bien podían presentársele a cualquier humano en su lucha por subsistir y conducir su existencia en sociedad. Con ello, templaban el carácter de los ciudadanos, preparaban su sensibilidad ante los sinsabores que vienen incluidos en el paquete de la vida, ensanchaban su imaginario sobre lo que significaba vivir según las leyes del estado y a expensas de las posibilidades hostiles que siempre subyacen al deseo (en esencia irresoluto) de vivir plenamente "entre las altas aspiraciones y los duros límites que la vida implica" (Nussbaum, 2006, p. 27ob. Cit.).

Esa batalla entre los deseos más primitivos y amorfos que sacudían incluso a las almas más ecuánimes y valerosas, y sobre cuyo dominio se declaraban impedidas, por un lado; y los valores vinculantes (o eugenésicos) de la polis ateniense o de las convicciones morales sistemáticas, por el otro, "constituye uno de los temas predilectos de la tragedia, por cuanto experiencias tan dolorosas desencadenadas por dicha tensión que ponía al límite la capacidad de padecimiento del héroe trágico, suscitan naturalmente ciertos interrogantes sobre la posibilidad de su eliminación" (Nussbaum, 1995, p. 89). No obstante, esto no significa que el deber ser político deba erigirse, frente a las posibilidades humanas reales, como instancia constrictiva absoluta, pues de un código moral tan sacralizado solo se derivarían exigencias encontradas que harían más chocante aún el conflicto trágico inmanente al hombre, y represarían lo peor de sí mismo para su posterior detonación.

Lo mismo sostiene un filósofo español contemporáneo a propósito del tema de la tolerancia y el pluralismo, tan en boga en los días que corren: Tal vez no hubo cosa más desfasada y más deshonesta que haberle pedido tanto 
al género humano con los ideales impolutos de la modernidad, en su carrera desbocada por el cumplimiento imperativo de una igualdad y libertad universales (Cruz, 1998), lo que devino en una comunidad ensimismada, obsesionada con la salvaguardia de sus propios motivos identitarios, en estado de sitio, con una imaginación moral incapaz de trascender los contornos de su propia sensibilidad para echar un vistazo a las posibilidades de un bien público equilibrado.

En la misma línea argumental, un comentario de Sábato en su ensayo La resistencia (2003) parece honrar también esa concepción de hombre que tanto rescata Martha Nussbaum (1995) de los griegos clásicos:

La vida es un equilibrio tremendo entre el ángel y la bestia. No podemos hablar del hombre como si fuera un ángel, y no debemos hacerlo. Pero tampoco como si fuera una bestia, porque el hombre es capaz de las peores atrocidades, pero también capaz de los más grandes y puros heroísmos (p. 91).

Pero, parece que así no lo han entendido todavía muchos organismos actuales al servicio de la pedagogía, que, aun cuando pregonen fórmulas retóricamente elegantes en favor de que la educación emocional, no han sabido guiar la formación de buenos ciudadanos. Es más, sin entrar a juzgar la posibilidad de estar orientado por un fin bienintencionado, los discursos sobre tolerancia y respeto impartidos en las escuelas, parecen estar paradójicamente inspirados en la vanidad narcisista de la que justamente nos previene Nussbaum, o ser abducidos por narciso en el camino de su aplicación. Esto ocurre justamente en el momento en que tales discursos acaban promoviendo una suerte de blindaje contra todo lo que el demandante de respeto suponga una amenaza inminente contra su integridad axiológica, cognitiva, estética, sexual o de cualquier otra índole identitaria, pues resulta que ésta no puede ser manoseada, cuestionada ni mucho menos puesta en entredicho por ningún intruso so pena de ser señalado, este último, como intolerante, violento y hasta insurgente ante los ojos de la ley. 


\section{Respuestas narcisistas en nombre del derecho}

Sí, aunque parezca exagerado y cueste reconocerlo, el aparato jurídico patrocina, en cierta medida, estas lógicas narcisistas. ¿Cómo así? Pues que usualmente este tipo de proceder legalista, lejos de suministrar los canales dialógicos necesarios para comunicar las diferencias, no posibilitan sinergias comunicacionales entre disimilitudes étnicas, éticas, políticas, sexuales, etc. Todo lo contrario: funciona como un represamiento (o silenciamiento) prudencial de las más variopintas convicciones, como una consigna que hace de la neutralidad ideológica un fetiche; que invita a que nos transparentemos, a que todos nos miremos de lejitos suponiéndonos (e incluso temiéndonos) una amenaza potencial para el otro, y con un recurso jurídico a la mano (generalmente la demanda o la tutela) por si acaso se produce un ataque.

Todo ello ocurre porque a ese otro, al igual que a mí, no le interesa en lo más mínimo socializar ni confrontar en sano ejercicio argumental y dialéctico sus propias convicciones frente a otras que de entrada no le convencen, sino imponerlas como imperativo obligante que pesa sobre el resto en función del respaldo jurídico que detentan: $O$ me toleras por la fuerza que me otorga la jurisdicción nacional e internacional o te ataco en nombre de esa ley y por encima incluso de tu voluntad de resistencia.

Pareciera ser ese el mensaje implícito que prolifera hoy en las consignas aparentemente más pacifistas alusivas a la convivencia ciudadana; pareciera ser narciso el que se toma la vocería de los discursos malversados de la tolerancia, el que margina en nombre de esas políticas nominalmente (y solo nominalmente) incluyentes. Digo esto porque cuando las leyes se nos antojan mecanismos de dominio, chantaje y venganza que nos proporcionan altitud protagónica por encima y delante de los demás, ahí está actuando narciso con la vanidad que lo caracteriza en su máximo esplendor, y no precisamente un sujeto que se reconoce parte de una sociedad gracias a la cual puede dotarse de rasgos distintivos en lógica de oposicióna la vez que de complementariedad; que se sabe parte de un todo y no una isla excepcional. 
Sobre este particular, el sociólogo Bauman (2013) también dirige su atención. Al analizar las dinámicas sociales contemporáneas en el contexto del caos migratorio provocado por la globalización y la desregulación del mercado, el autor presenta como un sofisma de distracción las 'iniciativas' que emprenden diversos actores políticos supuestamente consagrados a la pacificación de las ebullentes refriegas étnicas, religiosas y culturales al interior de la ciudadanía. Según este pensador, se consigue (e incluso se persigue) en realidad es el efecto contrario: perpetuar (consciente e inconscientemente) el círculo vicioso de los enfrentamientos violentos y la dispersión de intereses narcisistas, incapaces de trascender los límites privados del yo; y de avistar al otro como semejante con el que se comparte a grandes rasgos la aspiración a un mejor presente y a un futuro promisorio.

Por consiguiente, incapaces de pensarse como un todo potencialmente capaz de canalizar esfuerzos conjuntos de resistencia frente a las injusticias sociales, y más bien movidos en esa lógica impulsada desde los mismas políticas gubernamentales que afianzan las barreras entre comunidades y sujetos mientras se erigen jueces imparciales del caos (que robustecen la tendencia al narcicismo antes que replantear sus alcances nocivos), los individuos terminan por figurar, en la perspectiva de Bauman (2013), como piezas desperdigadas que "luchan cuerpo a cuerpo contra su propio, particular y singular tipo de opresión, separadamente y sin ayuda, observando con recelo a sus semejantes desafortunados que también hacen lo mismo" (Bauman, 2013, p. 40).

Circunscritos al centro gravitatorio de la propia individualidad resguardada, conforme al funcionamiento de la lógica cultural posmoderna, narciso termina tomándose entonces la vocería de las disposiciones éticas fragmentarias, las cuales no sobrepasarán como marco de acción el propio horizonte de los intereses personales, ni mucho menos contemplarán un entrecruzamiento intersubjetivo posible entre tales disposiciones y las del resto de la comunidad. Esto, según lo concibe Bauman, deviene incompetencia social, desde el mismo momento en que el pánico y la política del miedo (el estado de sitio) que sustenta tal proceder, es el mismo que sustenta, en 
consecuencia, la indiferencia frente a las manipulaciones de quienes orquestan las reglas de un juego egoísta. El juego, Bauman (2013) lo resume en estas palabras: "cuando los pobres se pelean con los pobres, los ricos tienen todas las razones para frotarse las manos con alegría" (pág 41).

$Y$ no es que este tipo de reflexiones posean un grado de abstracción a años luz de la realidad observable del día a día. Muy por el contrario: es la experiencia misma de las relaciones interpersonales la que posibilita conjeturar que el relato narcisista sigue estando ahí, camuflado aun en medio de aquellos discursos irreflexivos de respeto y entendimiento interpersonal que tanto citamos, y que se supone han de mantenerlo a raya.

Me referiré a tres experiencias puntuales que refuerzan esa tesis, extraída ambas de mi participación como filósofo en diversos proyectos de índole social dentro del país:

1. X abogado calificó una vez de demasiado ideológico un texto propuesto por mí como material evaluativo para la prueba de comprensión de lectura de $\mathrm{Y}$ concurso público para aspirantes a servidores estatales. Las psicómetras encargadas de validar cada uno de los ítems que conformarían la prueba simpatizaron algo coléricas con la sentencia de este señor y satanizaron el fragmento argumentando que un texto como ese despertaría muchas suspicacias en los evaluados, quienes no dudarían (los más tocados en sus delicadas axiologías, supongo) en interponer una demanda por percudir sus disposiciones intelectuales a la hora de contestar las preguntas con afrentas ideológicas de semejante calibre. El texto era un valiente editorial que hablaba sobre la adopción de niños entre parejas homosexuales, y relacionaba los argumentos más aducidos por el bando a favor y en contra. No era más.

Pero, el abogado terminó agregando que nuestra entidad no estaba dispuesta a elevar sus costos en la etapa de reclamaciones por concepto de demandas difíciles, así que me armé de una prudencia hobbesiana y opté por decir y no decir, por jugar al juego impracticable de la neutralidad.

2.Trabajando como transformador curricular en un proyecto educativo distrital $\mathrm{X}$, y mientras diseñábamos el plan de ejecución de las acciones afirmativas en cuanto a enfoque diferencial, convivencia y ciudadanía en los 
diferentes colegios adscritos al convenio, cuatro de los cinco profesionales allí reunidos propusieron no implementar ninguna actividad que pudiera comprometer nuestras convicciones al respecto, al punto de poder echarnos encima a padres de familia, a docentes, hasta a los mismos niños y por qué no al implacable peso de la ley. En ese instante todos pensaron en videítos sencillos, en hacer discursos más declarativos que detallistas sobre el respeto por la diferencia y cositas por el estilo, porque no fuera a ser que 'quedáramos sin trabajo'.

3. Haciendo las veces de árbitro en el debate ético sobre el carácter o punitivo o preventivo que debían tener los manuales de convivencia de las escuelas distritales, me topé con un prestigioso abogado (decano de la facultad de educación de una importante universidad capitalina, por cierto) que me confesó a solas, en su oficina, estar en favor de la punición, pues en ese mercado jugoso había encontrado la forma de taparse en plata; es decir, interponiendo demandas costosísimas a los planteles en favor de los estudiantes ofendidos por el detalle más ínfimo que pudiera probarse como agravio o atentado psicológico hacia ellos. En efecto, así parece funcionar ahora la relación de poder docente-estudiante ${ }^{5}$. Es ahora el estudiante depositario de todos los derechos habidos y por haber, empoderado ad infinitum; y el docente, por su parte, un autómata de los imperativos más utópicos y absurdos, una máquina de reproducir exclusivamente en su educando sensaciones positivas a riesgo de ser denunciado y castigado si tal intención llegara a desvariar en algún momento; si por alguna circunstancia se le escaparan en su discurso y en su carácter pistas de su más recóndita humanidad y quedara al descubierto frente al estudiantado, quien no desaprovecha la oportunidad para hacer lo que en esta situación corresponde hacer: denunciar y hacerse ver como protagonista jurídicamente superior.

Paralelo a ese proceder narcisista que se constata en las relaciones interpersonales de la vida escolar, se pregonan, paradójicamente, en el marco

\footnotetext{
${ }^{5}$ Hay de hecho una imagen que satiriza esta cuestión mediante dos escenarios en los que el estudiante no cumplió con la tarea: en el primero de ellos, se muestra a los padres regañando al niño enfrente del profesor. En el segundo (época actual), se muestra a los padres y al niño yéndosele encima al profesor con insultos y cara de indignados, por haber reprobado la acción del niño que no hizo la tarea.
} 
de políticas públicas de escritorio, fórmulas retóricamente elegantes como esta: "La construcción de un currículo para la excelencia académica y la formación integral comprende que la Educación para la Ciudadanía y la Convivencia es una apuesta fundamental en la política educativa de la Bogotá Humana, en la medida en que es en relación con los otros y las otras como se construye tanto el ser como el saber" (Secretaría de Educación Distrital Bogotá, 2014, p. 19).

La inoperancia de tales pronunciamientos al interior de la vida escolar tal vez se deba a una acusación que lanza la filósofa norteamericana en contra de las muchas agendas pedagógicas que supuestamente salen alarmadas a mitigar la violencia: "En general, las propuestas para la educación no contemplan la psicología del desarrollo humano, con lo que resulta confuso saber cuáles son los problemas que se pretende resolver y los recursos que se poseen para resolverlos" (Nussbaum, 2014, p. 55). En otras palabras, no se adentran en el núcleo del relato narcisista: ni en la indefensión, ni en la impotencia, ni en la vergüenza, ni en la repugnancia, como sentimientos que suponen, en potencia, un peligro moral para la convivencia ciudadana de no ser encauzados estratégicamente en favor del pacifismo y la igualdad.

En el caso particular de la convivencia escolar, se patenta el modus operandi de Narciso porque la tolerancia perseguida es dictatorial antes que dialógica; es una proscripción delirante de los malentendidos, las diferencias de conciencia, el disenso, el debate, la exclusión, los prejuicios, aspectos todos que vienen dentro del paquete de lo humano, y que se supone deben ser resueltos dialécticamente (en lo posible) vía comunicación y no por vía del silenciamiento y el pánico punitivo.

Si todos figuran a la espera de cualquier actitud sospechosa para alertar sobre los supuestos perjuicios que dicha actitud puede allegar sobre su sensibilidad axiológica; y si todos se escandalizan cuando suena la palabra "ideología", no cabe esperar sino reacciones paranoicas que acaban por debilitar progresivamente la capacidad que, para enfrentar y evaluar los propios errores y desaciertos, debe cultivar la humanidad. De lo contrario, lo que haremos es debilitar la sensibilidad de una sociedad que debe estar preparada 
por igual, tanto para deleitarse en sus bondades, como para encarar con carácter y sin paranoias sus desaciertos y su proclividad al egoísmo narcisista.

Si el manual de convivencia es una mortaja que se vuelve cada vez más fina con cada nueva puntada que le agrega la legislación, en aras de que siga aprisionando herméticamente los 'comportamientos detestables' y los siga poniendo fuera de nuestra vista para que no afeen el panorama (más exactamente en un limbo silente que no contempla siguiera la defensa), entonces estos seguirán encontrando una válvula de escape para reaparecer recargados de mucha más violencia y vanidad que la vez anterior. Y así se repite el ciclo una vez más, formando un círculo vicioso en el que las directrices documentadas acabarán siendo siempre esa patrulla policial que llega horas después de ocurrido el asesinato. ¿Tiene acaso mucho sentido sacar de la frecuencia social lo 'detestable', para que luego vuelva a entrometerse provocando mucho más ruido que la vez anterior?

Pues, según Nussbaum (2014), aquel que haya logrado un discernimiento de su propia naturaleza dialéctica responderá que no tiene mucho sentido, y que para lograr configurar y difundir una ética ciudadana lo mayormente justa hay que interpelar estratégicamente aquellos impulsos que residen en lo más profundo de nuestra psiquis, hay que darle la pelea a Narciso. Ojalá sea desde los primeros años de vida, con la ayuda y la tutela de gestores que ya estén librando en sus propias vidas dicha batalla, avistando un orden civil pacifista e igualitario dentro de las posibilidades humanas.

Esto se consigue, conforme lo sugiere Nussbaum (2005) en el Cultivo de la humanidad, mediante recursos pedagógicos que no precisan mayor presupuesto financiero, tales como la imaginación narrativa. Mediante la incorporación genuina de obras literarias afines a las preocupaciones de las juventudes, es posible activar la capacidad de imaginar la situación de los semejantes.

Nussbaum (2005) destaca el valor de la poesía como fuente de expresividad que ayuda a conocer los sentimientos del otro, con los cuales pueden verse profundamente identificados los estudiantes. Asimismo, la 
filósofa propone ejercicios prácticos, como la escritura de cartas desde una perspectiva totalmente ajena a las circunstancias de enunciación de quien construye el mensaje. En ese sentido, comparte una experiencia memorable durante su ejercicio como asesora curricular en la Universidad de Chicago. Estudiantes heterosexuales escribieron cartas en las que imaginaron confesarles a sus padres su inclinación hacia personas de su mismo sexo.

Otra de las herramientas que la norteamericana recomienda es la recurrencia al performance y a los juegos de roles, ya que en estos se involucra un conocimiento genuino hacia el propio cuerpo y su capacidad expresiva; un conocimiento que puede mitigar la vergüenza y los prejuicios asociados a la violencia de géneros y a un conservadurismo que convierte a la mujer, a fuerza de sospechas sexuales, en objeto sexual.

En este punto, Nussbaum (2014) resalta las virtudes de Tagore, pues este líder democrático logró, mediante la danza, la visibilización de puntos ciegos de su propia cultura referentes a la coerción de género, específicamente contra las mujeres.

Estas y otras muchas herramientas que ofrecen los lenguajes estéticos del arte y la reflexión humanística en torno de los conceptos que automatizamos para mal sin siquiera darnos cuenta, pueden orientar una práctica educativa que fortalezca las competencias ciudadanas, si se deja de lado el temor infundado (e inoperante) de parecer colonizadores ideológicos al servicio de intereses políticos censurables, como a veces lo hacen ver quienes desdeñan de iniciativas realmente genuinas como las que propone Nussbaum (2005).

\section{Reflexiones finales en torno a las posibilidades de un orden civil pacífico e igualitario}

Recordemos que, antes que promover una tolerancia aislante e irreflexiva, basada en la demanda imparable de garantías jurídicas para cuanta aspiración aflore al interior de la ciudadanía, inclusive las más narcisistas (como por ejemplo el proyecto de ley que se discute por estos días en el congreso y que busca vetar la posibilidad de que sujetos solteros adopten porque estos no tipifican el ideal de familia católico), es preciso incentivar la 
comunicación razonada y argumentada entre los bandos amurallados, los cuales aducen, como argumento para el despliegue irrestricto de sus conciencias, una neutralidad amoral que, aseguran, subyace a las relaciones intersubjetivas de cualquier sociedad liberal.

Esto precisamente con el fin de mitigar una concepción malversada de lo que es liberalismo político, la cual deviene objeción frente a cualquier iniciativa de establecer rutas pedagógicas para incentivar un respeto real por las diferencias, tal y como lo ejemplifiqué líneas más arriba cuando conté la abstención prudencial de algunos profesores encargados de implementar acciones afirmativas en cuanto a enfoque diferencial y de género en colegios distritales de Bogotá: se abstuvieron porque podían ser tildados de colonizadores ideológicos, de llevar una agenda política bajo la manga, de violentar la libertad de conciencia ajena al pretender imponer una visión ética particular.

Como se supone que la posmodernidad desplazó para siempre al Estado-sol dieciochesco que antes iluminaba los senderos a recorrer, y que ahora los ciudadanos orbitan con total holgura (deben orbitar) alrededor de sus propias pautas morales, de sus propias fuerzas gravitacionales, que por lo general son asuntos menos trascendentales que el bien común y otros embelecos políticos. Como se supone que ahora la horma moral en la que entran está hecha a la justa medida de sus cuerpos y mentes (es de uso personal), entonces ahora despotrican y sospechan (por exceso) de cualquier asomo de hegemonía impuesta por una agenda pedagógica; y depositan sus esperanzas futuras, antes que en discursos "jartos" y abstractos de felicidad comunitaria a gran escala, en las promesas más simples que emanan de la ciencia y de la tecnología: tales como provisión de indumentaria al servicio de la resolución del estrés laboral, del perfeccionamiento inmunológico, del embellecimiento corporal, de la mitigación de la vejez, de la ampliación de la expectativa de vida, etc. En definitiva, en asuntos que hacen más parte del fuero íntimo de los individuos que de sus nexos sociales. 
De modo que, en un contexto como ese, Narciso adquiere total licencia para azuzar los deseos más primitivos y egoístas, y para hacernos creer, además, que al placer de autosatisfacernos y de regodearnos en nuestras propias libertades no hay por qué obstruirlo, ni hay por qué enfrentarlo con códigos morales que desbordan a todas luces el cercado de los predios personales que tanto defiende cualquier democracia liberal.

Esa objeción, según Nussbaum (2014), es un sofisma amparado en una supuesta neutralidad amoral que de suyo no predica el liberalismo político. Ella responde diciendo que el hecho de ser liberales no implica necesariamente prescindir de un horizonte axiológico capaz de orientar al cuerpo social por senderos amigables con el bienestar común. Todo lo contrario: del suelo mismo de lo que se tiene por liberalismo brotan valores esquemáticos como: respeto por la vida, respeto por la diferencia, solidaridad; valores todos que en su conjunto detentan a todas luces la fisonomía de una propuesta moral, de un cimiento axiológico sobre el que luego se levantan los respectivos contenidos privados de que están hechas las libertades individuales de los ciudadanos, cuyas garantías depende de que no pretendan desdibujar ese suelo que les permitió germinar. Sostiene Nussbaum (2006):

Los liberales no tienen por qué y no deberían sostener que la sociedad pueda dispensar de una moral compartida; solo tienen que decir que la moral compartida debería ser una moral políticamente liberal, que distinga entre valores políticos y constitucionales compartidos, y otros aspectos de la concepción general de las personas acerca de lo que es una buena vida. Estos últimos incluirían cuestiones de religión y -dejando de lado el daño no consentido a terceros- asuntos relativos a la conducta y a los deseos sexuales. Los liberales pueden añadir que la protección de la libertad en áreas de profunda significación personal es en sí misma una norma moral y un valor compartido, uno de los valores más apreciados en muchas sociedades. (p. 95)

Esta dificultad de carácter formal con que tropieza a menudo una defensa de la educación liberal cuando promueve y difunde algún tipo de programa educativo específico, acorde con los ideales de una democracia saludable, representó incluso una limitación en las teorizaciones clásicas de corte liberal que ofrecieron los grandes filósofos políticos de la llamada escuela contractualista moderna. 
Nussbaum (2014b) califica de demasiado prudentes las alusiones hechas por Locke y Kant a propósito de las garantías de los derechos básicos proclamados dentro de la filosofía liberal. Locke, por su lado, dice la autora, habiéndole concedido un espacio dentro de su argumentación al tema de la intolerancia como amenaza latente dentro del gobierno civil, sin embargo, no llega al punto de proponer expresamente un plan para mediar los conflictos provenientes de la coexistencia disímil de las creencias religiosas al interior de la Inglaterra de su época. Se limita solo a sugerir o a recomendar "a las iglesias a que aconsejaran a sus fieles sobre los deberes de paz y buena voluntad hacia los hombres" (Naussbaum, 2014b, p. 17), y a presentar la protección de la propiedad por parte del gobierno hacia los ciudadanos como una medida tardía, que solo actúa cuando ya ha habido efectos ilegítimos productos de la intolerancia irrestricta y desbocada.

Kant, por su parte, habiendo llegado incluso más allá de Locke en materia de reflexión sobre la tendencia al mal en la conducta humana, "argumenta que la mala conducta en sociedad no es un simple producto de las condiciones sociales imperantes en ese momento: tiene sus raíces en la naturaleza humana universal, que encierra ciertas tendencias al abuso de otras personas" (Nussbaum, 2014, p. 18), y habiendo señalado que los individuos "tienen el deber ético de integrarse en un grupo que refuerce las predisposiciones positivas que ya tienen, para que estas tengan mayores probabilidades de imponerse a las negativas" (Nussbaum, 2014, p. 18.), no obstante, tampoco adoptó medidas psicológicas para dirimir este tipo de situaciones. $Y$ esto, concluye Nussbaum, se debe a que tiende a creerse que un Estado liberal tiene las manos atadas a la hora de señalar derroteros morales por mor de su compromiso mismo con libertades como la de expresión y la de asociación.

De manera que, si la idea de una educación liberal no es, como bien lo señala Nussbaum (2014), incompatible con la dación de un suelo moral vinculante de la praxis ciudadana, es posible y legítimo encargarle a la educación, en tanto que esfera cultural pública de los estados, una labor fundamental como la de mantener a raya, o en un estado de negociación 
estratégico, todas aquellas pulsiones que amenacen con deteriorar la salud de un orden democrático. Sin irnos al extremo defectivo (sacralización deshonesta de lo humano), ni al extremo excesivo (hedonismo irresponsable que desdeña cualquier asomo de razón).

Así las cosas, cabe concluir, compartiendo la recomendación de Nussbaum (2014), que si la educación no se compromete con la incursión rigurosa en la psicobiología humana, con el ánimo de entendernos como sujetos biológicos y sociales al tiempo, los propósitos de la agenda educativa de las naciones serán solo principios abstractos anclados en neologismos promisorios y en fórmulas retóricamente elegantes que no tendrán piso alguno en la propia dinámica de participación conflictiva de los ciudadanos respecto de sí mismos, de su entorno y de sus semejantes.

\section{Referencias Bibliográficas}

Bauman, Z. (2013). La cultura en el mundo de la modernidad líquida. México : Fondo de Cultura Económica .

Cioran, E. (1998). Del inconveniente de haber nacido. Madrid: Taurus.

Cruz, M. (1998). Tolerancia o barbarie. Barcelona: Gedisa.

Elías, N. (2001). El proceso de la civilización. Investigaciones sociogenéticas y psicogenéticas. México: Fondo de Cultura Económica.

Moreno, J. (2015). Novela histórica colombiana e historiografía teleológica a finales del siglo $X X$. Santiago de Cali: Universidad del Valle.

Nussbaum, M. (1995). La fragilidad del bien. Fortuna y ética en la tragedia y la filosofía griega. Buenos Aires: Visor.

Nussbaum, M. (2005). El cultivo de la humanidad. Una defensa clásica de la reforma en la educación liberal. Madrid: Paidós.

Nussbaum, M. (2006). El ocultamiento de lo humano. Repugnancia, vergüenza y ley. Buenos Aires: Katz.

Nussbaum, M. (2012). Las fronteras de la justicia. Consideraciones sobre la exclusión. Madrid: Paidós.

Nussbaum, M. (2014). Emociones políticas. Por qué el amor es importante para la justicia. Barcelona: Paidós.

Nussbaum, M. (2014). Sin fines de lucro. Por qué la democracia necesita de las humanidades. Madrid: Katz.

Pratt, M. (2010). Ojos imperiales: Literatura de viajes y transculturación. México: Fondo de Cultura Económica.

Rama, Á. (1998). La ciudad letrada. Montevideo: Arca. 
Sábato, E. (2003). La resistencia. Bogotá: Planeta.

Sanín, C. (2008). El cuarto de "la muchacha". Semana.

Sección Educación. (31 de mayo de 2016). Nuevo sistema iguala condiciones para técnicos y profesionales. El Tiempo.

Secretaría de Educación Distrital Bogotá. (2014). Currículo para la excelencia académica y la formación integral. Orientaciones generales. Bogotá: Jerlee Digital Editores.

\section{Para citar este artículo:}

Bolivar, D. (2017). Covivencia ciudadana versus Narciso: la batalla por un orden civil pacífico e igualitario. Collectivus, Revista de Ciencias Sociales, 4(1), 126-154.

Doi: http://dx.doi.org/10.15648/Coll.1.2017.7 